Revista de la red interuniversitaria de estudios sobre las literaturas rioplatenses contemporáneas en Francia

Hors-série | 2019

Ricardo Piglia: Cierta idea de literatura

\title{
Piglia/Renzi, postrero desliz
}

\section{Julio Premat}

\section{OpenEdition}

\section{Journals}

\section{Edición electrónica}

URL: http://journals.openedition.org/lirico/7907

DOI: $10.4000 /$ lirico.7907

ISSN: 2262-8339

Editor

Réseau interuniversitaire d'étude des littératures contemporaines du Río de la Plata

\section{Referencia electrónica}

Julio Premat, «Piglia/Renzi, postrero desliz », Cuadernos LIRICO [En línea], Hors-série | 2019, Puesto en línea el 16 febrero 2019, consultado el 09 mayo 2019. URL : http://journals.openedition.org/lirico/7907 ; DOI : 10.4000/lirico.7907

Este documento fue generado automáticamente el 9 mayo 2019.

\section{(c) $($ ) $(9)$}

Cuadernos LIRICO está distribuido bajo una Licencia Creative Commons Atribución-NoComercialSinDerivar 4.0 Internacional. 


\title{
Piglia/Renzi, postrero desliz
}

\author{
Julio Premat
}

...quand'era in parte altr'uom da quel ch'i' sono

Petrarca, Canzionere, 1

\section{Una paradoja}

1 La preparación de los tres volúmenes de Los diarios de Emilio Renzi fue llevada a cabo en condiciones extraordinarias, hechas a la vez de un paroxismo agónico y de una escritura que, aunque se situaba en el presente, ya era o ya se sabía póstuma. Semejante circunstancia no es para nada anodina a la hora de evaluar, en este caso preciso, las transformaciones que la muerte de un gran escritor no deja de suscitar en sus textos ya publicados. Me refiero, entre otras cosas, al valor de cierre y de, digamos, fatalidad, que adquiere todo gesto anterior al fallecimiento, valores creados por las hoy habituales ediciones postreras de materiales inéditos. En Piglia, un aura, un pathos, una adhesión insensata a la propia creación, acompañan el trabajo de fin de una producción y de una vida literarias; en esa perspectiva, el ejemplo recuerda otros momentos legendarios, como el de Proust borroneando las pruebas de galera de En busca del tiempo perdido, con un ímpetu irrefrenable radicalmente opuesto al desfallecimiento progresivo de su cuerpo.

La transformación de lo ya escrito por Piglia concierne ante todo el lugar y la función que cabe atribuirle a la figura de Emilio Renzi en el proyecto; en la larga serie de espejeos entre vida y ficción, entre verdad y falsedad, que caracterizan a sus textos, el desplazamiento hacia Renzi fue la última trama consolidada por el escritor (Kohan 2017). Sin ser radicalmente diferentes ni sorpresivos de cara a la obra ya escrita, los Diarios funcionan como el desenlace de una metaficción que engloba toda una trayectoria; así, estos textos fragmentarios implican lo definitivo, haciendo de los libros ya editados y obsesivamente corregidos, borradores. Hoy, ahora, todo parece haber preparado, casi serenamente, este desenlace. Comenta Juan Villoro (2018) que Piglia solía bromear diciendo que "había escrito todos sus demás libros para darse a conocer como un autor al que después le pudieran publicar sus papeles más personales" y anota Jorge Carrión (2017) que la publicación de los tres volúmenes de los Diarios cambió la perspectiva al 
volver visible que "debajo de todas sus novelas y todos sus ensayos estaba, decisiva, una gran forma, un gran género, de no ficción cotidiana".

3 Los últimos años, concentrados entonces prioritariamente en publicar un material de índole íntima, tuvieron un efecto tan espectacular como paradójico: en vez de acentuar el aspecto autobiográfico de su obra, pusieron de relieve la operación fabuladora más fuerte de su proyecto, a saber, el desplazamiento del yo biográfico a un personaje, ese personaje de autor que se dio en llamar Emilio Renzi. Así, la escritura, en vez de dar cuenta de la vida sería, según la expresión de Piglia en Crítica y ficción, "el lugar donde los borradores de la vida son posibles" (2001a: 109), es decir el lugar de esbozar o soñar una vida efímera, inestable, corregible. Los Diarios, gracias al cambio de identidad del hombre de quien se cuenta la existencia, pasan de la transmisión de la verdad más inmediata (usual en los diarios íntimos) a la ficción (la proyección de sí mismo en un imposible, en otro, en un personaje de papel).

4 Puede afirmarse también, dentro de este sistema de insistentes espejeos y pudores repetidos, que la ficción y la autoparodia consecuente son los únicos medios disponibles para decir algo sobre la vida del autor empírico; sólo se puede hablar de ella usando la literatura, es decir la "ilusión de falsedad" (Piglia 2000a: 28). Un buen ejemplo serían las alusiones a la enfermedad que figuran en los textos liminares o finales de los Diarios o aquellas que Piglia hace sobre el tema en la película de Andrés Di Tella, 327 cuadernos: el tono humorístico y liviano con los que se insinúa una verdad trágica (lo ineluctable de un proceso degenerativo y la inminencia de la muerte), es a la vez una distanciación, una transformación de lo dramático en ficción, pero es también un modo de incluir, en lo escrito o en lo dicho públicamente, un acontecimiento que, por su radicalidad, parece ser del orden de lo informulable. Esta frontera se alcanza con las últimas frases del tomo tres, frases entrecortadas que no llegan a constituir un discurso y de las cuales selecciono algunas:

Siempre quise ser sólo el hombre que escribe. Me he refugiado en la mente, en el

lenguaje y en el porvenir. [...]

El papagayo en una jaula.

La silla de ruedas, el andar mecánico, el cuerpo metálico.

La enfermedad como garantía de lucidez extrema.

Una dolencia pasajera. [...]

Si uno puede usar su cuerpo, lo que dice no importa.

El genio es la invalidez (2017: 294).

En estos atisbos discursivos se entiende que la omisión, la despersonalización, los dispositivos de la ficción, la retórica de la metáfora y el recurso a la expresión aforística, son modos de decir aquello que no se puede decir o seguir diciendo: son los modos del pudor (Rodríguez Pérsico 2017: 63). Todos pensamos en algún momento que las trágicas condiciones del final de la vida de Piglia sonaban como ecos inquietantes de sus obsesiones literarias; también lo pensamos sobre la enfermedad que le impuso a Saer no terminar $L a$ grande, dejando su imponente edificio novelístico en alguna medida abierto, disponible para inconcebibles prolongaciones futuras. Los proyectos fuertes de ciertos escritores integran en ellos, sorprendentemente, la contingencia y más allá, lo imprevisible, como lo es la enfermedad y la muerte.

Piglia cierra en todo caso su obra y su vida con una paradoja: la ficción se impone en el momento del acercamiento máximo a la vivencia, o sea que el recurso a las máscaras de lo fabulado se vuelve el único modo de atravesar lo impensable. La imposibilidad de vivir y la búsqueda consecuente de una escritura reemplazan, precisamente, el relato de una 
existencia humana. La literatura en vez de la vida: esto forma parte, según el mismo Piglia, de la definición de Renzi como personaje: “[...] a Renzi sólo le interesa la literatura, habla siempre con citas, vive 'literariamente"' (2001a: 110). Para morir literariamente hay que ser, por lo tanto, Renzi.

\section{Estilos de un final}

7 Los Diarios, cuya publicación fue tantas veces anunciada y postergada, repiten ideas conocidas para un lector habitual de Piglia autor, exponen dudas, tensiones y conflictos propios de una carrera literaria, contienen un material de orden genético que permite fechar y rastrear las etapas de un proceso de escritura, así como esbozan un vívido panorama de la vida literaria e intelectual de Buenos Aires, sobre todo en los años sesenta y setenta. Sin embargo, si algo surge, no nuevo, pero al menos inesperado, es el relato de la ardua emergencia de una identidad de autor, transformada ulteriormente en una identidad ficticia (cuando los cuadernos son corregidos para convertirse en los Diarios de Emilio Renzi), es decir todas esas reflexiones que acompañan la definición progresiva de una figura de escritor y la complejísima relación que se establece entre ese heterónimo y la escritura. En Piglia se es escritor antes de escribir (o se intenta ser escritor en lecturas, gestos, tonos, antes de serlo por la validación obtenida con una bibliografía reconocida), por lo que la publicación de los Diarios orienta la lectura hacia los sentidos y efectos de ese paso del "hacer" (escribir) a "ser" (ser escritor) gracias al desplazamiento de Ricardo a Emilio y de Piglia a Renzi. Por lo tanto, el cambio de nombre, la elección del nombre, están enfatizados y pasan a jugar un papel esencial aunque postrero en la fundación y el desarrollo de una "vida literaria".

8 Cierto es que la historia del personaje Emilio Renzi (su primera aparición en el cuento "La invasión", su definición progresiva) se confunde con la historia de la obra narrativa. En particular, es interesante notar que su papel protagónico en Respiración artificial va a la par de lo que sería el final de un proceso de entrada en literatura y de afirmación como escritor de parte de Piglia, proceso arduo y extenso (desde, digamos, 1957, cuando comienza el diario, o desde la primera edición de La invasión, 1967, hasta 1980, fecha de publicación exitosa de la novela). Significativamente, Piglia afirma que Respiración artificial "se escribió como la educación de Renzi", un personaje que pasa, entonces, "por una iniciación. Ese sería el punto en que el personaje se construye” (2001a: 110-111). Terminar de hacerse escritor (Piglia) y construir al personaje de Renzi son simétricos y están interconectados.

9 Así se define un alter ego prolongado o repetido que, de relato en relato, aparece con características que se estabilizan entonces en Respiración artificial (un poco a la manera de Belano en Bolaño, o, más difusamente, de Tomatis o Pichón Garay en Saer), un alter ego a la vez autobiográfico y autoparódico (González Álvarez 2009: 198-208). En algunos períodos de la producción su presencia se difumina por la inclusión de un personaje llamado Renzi que, aunque sea secundario en la intriga, supone siempre en la obra una apropiación de lo escrito y señala su pertenencia a un sistema. Es en ese sentido que Renzi es una firma oculta, pero gracias a un mecanismo que pone en escena, como en tantos otros niveles, el ser/no ser de la literatura, la verdad/falsedad de todo relato; en sentido inverso, la figura de Piglia también aparece como personaje en otros textos (por ejemplo, "Homenaje a Roberto Arlt"), en una perspectiva de inversiones y deformaciones múltiples que tienen que ver con lo apócrifo, el plagio, la presentación de lo real como invención y 
otras constantes de la obra, ya que el nombre verdadero aparece como un seudónimo exponencial: "Utilizar mi propio nombre para señalar a un narrador ficticio es invertir el mecanismo del seudónimo" (2016a: 72).

10 La operación de sustitución Piglia/Renzi en los cuadernos fue organizada y expuesta junto con la preparación de la publicación: el documental de Di Tella, los textos preliminares o intercalados en cada tomo, el trabajo de intervención que excluye todo lo que, pareciera, no se corresponde o no dialoga con los textos publicados. Coincidiendo con lo dicho más arriba, señalemos que desde los años ochenta (o sea poco después del desenlace de esos extraños beginnings con Respiración artificial), Piglia se refiere a sus diarios en entrevistas, integra fragmentos reales o inventados en ficciones y ensayos, prepublica fragmentos, contacta eventuales archivistas o investigadores que pudiesen ocuparse de ellos. En ese sentido la partida de Princeton, la jubilación por lo tanto y el regreso a Buenos Aires abren, legendariamente, otra etapa en un proceso que está ampliamente representado y seguramente fabulado en la película. En ella pasamos de la mudanza de libros y cuadernos de la oficina de Princeton a las dificultades, fruto de la enfermedad, de escribir, pasando por muchas escenas en las que, siguiendo un azar ficticio, Piglia abre y lee algún fragmento de los diarios.

11 En un momento dado, y es seguramente el momento crucial del documental, Piglia hace lo que él denomina "una confesión", la confesión de un "secreto":

A veces tengo la fantasía de publicar el diario como el diario de Emilio Renzi ¿no? Es decir, darle a un personaje que he construido a lo largo de los libros, darle mi vida como quien dice, ¿no? Va a ser todo lo que he vivido, pero nada más que si aparece como el diario de Emilio Renzi, se produce el tic que a mí me interesa, que es porque... qué pasa acá... No sé si voy a tener el coraje de hacerlo, digamos, es como que yo quedo ahí... Pero ésa es una de las ideas que me vuelven siempre, es "sería bueno publicar este diario con mi vida tal cual es, pero publicarlo como Ricardo Piglia, El diario de Emilio Renzi”, ¿no? (2015)

La sinceridad de esa confesión y su carácter supuestamente "secreto" debe, por supuesto, ser puesta en duda: en la película Piglia "hace" de Piglia o, mejor, de Renzi. Lo que cuenta es la teatralización que enfatiza una decisión resemantizadora de lo escrito hasta entonces; las páginas del diario que intentan acercarse más a la experiencia, al día a día de la vivencia, $y$, por lo tanto, a un modo de, digamos, expresión subjetiva del sujeto si no a una verdad del sujeto, esas páginas son las de otro, las de un personaje de ficción, como lo afirmaba Barthes en preámbulo a sus notas autobiográficas ("Todo esto debe ser considerado como algo dicho por un personaje de novela") (1978:1).

Sea como fuere, la intervención en sus cuadernos (cambio de todas las referencias a Ricardo Piglia por referencias a Emilio Renzi), más los textos introductorios, más entonces el cambio de nombre como desenlace de un interrogante expuesto en los Diarios y fuera de ellos sobre estrategias posibles de edición de sus notas personales, hacen de estos tres libros libros actuales, libros póstumos, libros de la década del diez de nuestro siglo. Son los últimos libros escritos por Piglia aunque buena parte de lo que contienen haya sido redactado antes.

\section{Un desplazamiento}

14 El dispositivo de desplazamiento en el nombre del autor hacia aquella parte no mencionada, simple identidad civil sin operatividad en la denominación habitual 
(segundo nombre, apellido de la madre), implica el paso a una zona oculta, ignorada, en relación con la experiencia pero acallada en la vida cotidiana. Ser autor es proceder a una autofundación y a un autobautismo, como en el clásico ejemplo del seudónimo, es elegir un nombre falso (un nombre que no se usa) para producir un choque y un diferencial identitario: en la tapa de los Diarios publicados por Anagrama tenemos el nombre de autor (Ricardo Piglia) y un atributo de pertenencia de esos mismos Diarios, que no coinciden (son los Diarios de Emilio Renzi). A pesar de esa disociación, el gesto no introduce un heterónimo absoluto, no es una invención plena, con ribetes legendarios, como lo es el armonioso Pablo Neruda en vez del altisonante Ricardo Eliécer Neftalí Reyes Basoalto, o con tonos irónico-programáticos, como el Juan Emar (j'en ai marre) que reemplaza Alvaro Yáñez Bianchi. Tampoco es la leve alteración que incluye en el férreo significante paterno una marca personal, una adaptación, una corrección; Faulkner le agrega una " $u$ " a su nombre y Freud retira el "is" de Sigismund. Aquí el hombre se elige a sí mismo, poniendo en primer plano aquellos signos del nombre que, aunque ya existentes, resultaban desconocidos.

El mecanismo lleva la impronta de una novela familiar (en el sentido de imaginar otros padres o linajes), una novela familiar que no cuaja en peripecias pero constituye el resabio de una imaginación novelesca primitiva y que lleva a la proliferación de los "si... entonces" de la ficción. Porque no hay una autoinvención plena ni un paso a querer ser radicalmente otro, sino una intervención en lo heredado: un desplazamiento sintagmático hacia lo lateral, hacia lo que sitúa más allá. Si la identidad de un individuo se define por una denominación que estabiliza y organiza las diferentes facetas de su existencia social y si la denominación es invariable (es el nombre elegido por los padres antes del nacimiento, el apellido transmitido por vía paterna en vínculo con un remoto linaje), intervenir y cambiar ese nombre es buscar una especificidad: "aquello que has heredado de tus padres, adquiérelo para poseerlo", decía Goethe. Freud, que citaba a menudo esta frase, supone que no hay transmisión posible sin la existencia de una comunidad previa ya que el sujeto singular no es más que el eslabón, el sirviente, el beneficiario y el heredero de la cadena intersubjetiva de la que procede y que lo precede (Kaës 1993: 4). Al nombre se lo transmite como una marca indeleble de pertenencia.

En disonancia con esto, aquí, al padre se lo desplaza, poniendo otra pertenencia en juego, una pertenencia que tiene que ver con la familia de la madre y que no sería ajena a la representación, en los relatos, de la voz literaria como una voz femenina (Orecchia Havas 2010); esto parece confirmarse al comienzo de los Diarios cuando se evocan recuerdos de infancia y de escritura asociados justamente a la madre primero y a deseables mujeres luego ("Aprendemos a leer antes de aprender a escribir y son las mujeres quienes nos enseñan a leer") (2015a: 20). Se pone así en escena una libertad de invención o de transgresión mayor, libertad legendariamente situada del lado de lo femenino. Un doble linaje, entre líneas, es subrayado, recordando las fulgurantes hipótesis de Piglia (2004) sobre la fabulación familiar de Borges (un doble linaje que es nada menos que el cimiento de una apropiación del conjunto de bienes que constituyen la cultura argentina).

El simulacro del yo, equivalente a los espejismos identitarios que conlleva toda figura de autor, va de par, por otro lado, con la función que Piglia le atribuyó siempre al ensayo en su proyecto. Un ensayo que pudo ser "escrito" con lo que él mismo llamaría un "estilo" (ciertos modismos y tipo de giros) y en los cuales cabe integrar esos textos que presentan la forma de un diario, verdadero o apócrifo ("Notas sobre Macedonio en un Diario", "Notas sobre literatura en un Diario", "Diario de un loco"), tanto como la palabra de un 
"Piglia oral" (en entrevistas, a veces transformadas en libros de gran visibilidad como Crítica y ficción y últimamente en ediciones escritas o audiovisuales de conferencias y cursos). En todo esto se percibe con nitidez la recuperación de dispositivos usados con virtuosismo por su ilustre antecesor en la materia, Borges, que resulta ser "una cantera inagotable" (Rodríguez Pérsico 2017: 66; Balderston 2012); por ejemplo en las transformaciones de lo ya publicado gracias a declaraciones falaces, en una visión de la literatura hecha de puestas en escena del yo en espacios públicos, en la repetición mitificante de ciertas anécdotas biográficas (o biografemas) como la partida a Mar del Plata o la relación con los archivos del abuelo, todo lo cual encuentra equivalentes en la trayectoria de su antecesor. En otros niveles se asemejan también las intervenciones constantes en las ediciones o reediciones (redistribuyendo series, reescribiendo, censurando, poniendo el énfasis en tal o cual texto como cimiento), el uso de prólogos y epílogos como lugares considerados estratégicos de construcción o de difuminación del sentido (los introducidos en la edición de los Diarios son particularmente espectaculares en esa perspectiva). Incluso son similares las fabulaciones de una recepción futura: en el epílogo de la Obra completa de 1974 Borges imagina una entrada enciclopédica sobre él publicada en 2074 y en el tomo III de los Diarios, en "Un día en la vida", se incluye una fantasía futurista sobre los diarios, convertidos en un libro hallado en las aguas, en algún momento posterior al siglo XXII (2017: 234-240).

En Borges, los gestos de este tipo, constantes, tienden a sustentar una idea de obra, de gran obra, dándole coherencia y magnitud entonces a una trayectoria basada en aludir a libros ideales sin intentar escribirlos. En Piglia, que podríamos ver como un Borges manierista (Carrión 2008a), simétricamente, esta profusión de lo dicho, tanto como el recurso al diario (a lo ya escrito), no son ajenos tampoco a una paradójica dificultad para escribir, a una escritura pospuesta o imposible de libros ideales, mencionados y desechados. En alguna medida, Piglia escribe poco pero publica mucho. Lo que para Borges fue el imponente tomo de la Obra completa de 1974, cristalización unificante de una producción, para Piglia lo son por lo tanto los Diarios.

El desplazamiento en la filiación conlleva entonces otra elección, la de la figura de Borges que transmite modos tan oximorónicos como eficaces de ser un gran autor. En todo caso, el carácter electivo de una identidad, oculta bajo el nombre habitual es, claro está, una modalidad de relación con el pasado literario. En lo heredado (el segundo nombre, el apellido de la madre, pero también en las diferentes tradiciones de la literatura argentina, las visibles y las marginadas), en lo que constituyó al sujeto escritor y que es anterior a él, se busca la grieta, lo inusitado, lo olvidado, es decir se propulsa al centro y a la máxima visibilidad algo presente pero secreto, algo recibido pero que no era operativo, en un programa de afirmación de una particularidad desde lo que ya fue. $O$ sea, una manera de ser que amplía las lecturas de una tradición reformulada. No se trata solamente de inventarse sino de fabular a partir de lo recibido, deslizando en ello un cambio imprevisible que, con todo, no tira por la borda el pasado, sino que lo desmonta, se lo apropia, lo imagina.

Es en esta perspectiva que se define una singularidad autoral, en la medida en que sus lecturas, ensayos y cursos, que desestabilizan las lecturas habituales y proponen hipótesis a menudo insólitas sobre la biblioteca literaria argentina, son los de un escritor o están reivindicados como tales (Piglia 2017: 136-137). Es decir que sus hipótesis críticas pasan por, a su vez, una serie de desplazamientos, por una relectura renovadora de las 
jerarquías establecidas y por intentos, desde una posición de escritura, de reorganizar su sentido y sus perspectivas.

21 La especificidad de Piglia o sus maneras de insertarse en un momento preciso de la literatura argentina tienen que ver con lo dicho; su "vanguardia" (la "cuarta" vanguardia, para retomar ese panorama de la producción de escritores de su generación organizada alrededor de tres figuras, Saer, Puig y Walsh) (2016b) es precisamente la del escritorensayista -no escribir ficción sino combinar inextricablemente crítica y ficción, retomando un título suyo-. En los Diarios a esta constatación, conocida, se le agrega un relato: ser un escritor ensayista deviene una ficción: "Por mi parte, como Macedonio o Musil, veo en el ensayo el camino de renovación, es decir, aspiro a la apertura que trae una consistencia de varios estilos que se articulan novelísticamente, aunque no hayan nacido como formas narrativas" (54). Porque lo que se intenta es tomar lo mismo pero poniendo el acento en otro aspecto, se trata de leer de otra manera y así ser de otra manera cuando se escribe. El carácter atípico de la producción de Piglia que busca su especificidad en la mezcla de ensayo y ficción se juega y define, seguramente, en esta reflexión, puesta en escena y despliegue progresivos de una identidad de escritor, arduamente generada. Desplazarse hacia Renzi, pensar a la literatura siendo Renzi, es el lugar de Piglia.

\section{Despersonalización}

La cuestión del nombre o de la identidad del que escribe, y la de la otredad intrínseca que supone, son temáticas recurrentes en la obra, $y$, sin sorpresas, también en el documental de Di Tella; Piglia repite en él una frase, ya enunciada con variantes en conferencias anteriores: "La literatura es un lugar en donde siempre es otro el que habla". En los Diarios se comenta a menudo la transcripción de los cuadernos, los tipos de lectura o de relectura posible de ellos, la quimera de una publicación futura y se concluye, también a menudo, en una posposición involuntaria o en una fantasía de publicación al final de la vida. Asimismo, la escritura, el comentario y la edición de los Diarios condensan, cristalizan, una aguda teoría sobre la literatura. Frente a esto, los relatos que se escriben o proyectan parecen aplicaciones, remedos, ser casi superfluos, o bien llevan la sombra de una esterilidad amenazante. Hasta cierto punto, la teoría sobre el yo o la dinámica verdad/falsedad (biográfica, histórica) tienen la capacidad de abarcar el resto de lo ya publicado, haciendo de los cuadernos, reelaborados, el centro de la obra.

En todo caso, esta otra vertiente de la creación es indisociable de la figura de Renzi. El procedimiento no sólo se confunde con la escritura en sí, sino que la dispara, la justifica; es el primer paso para encontrar una voz propia "que no será necesariamente la mía, es decir, la que uso en la vida. Escribir con la sinceridad de un sujeto al que no conozco y que sólo aparece -o se asoma- cuando escribo" (2016a: 105). La despersonalización (ser Renzi y no Piglia) resulta entonces más importante que las técnicas o los procedimientos narrativos. Así, dice:

[... puedo] justificar mi despersonalización al escribir (ésa es la condición de la prosa para mí, ser otro cuando escribo, o mejor, ser otro para escribir). Justifico de ese modo mi esquizofrenia (leve), me desdoblo, pero eso es lo más difícil, y así justifico el trabajo (no por su contenido ni por su resultado) (2016a: 113). habla- no existe. Así defino yo la ficción: todo es o puede ser verdad, pero la clave del 
procedimiento es que quien narra es un sujeto imaginario" (2016a: 373). En estas citas se ve, por un lado, el trasfondo identitario de muchas operaciones textuales de sus relatos $y$, de nuevo, la intrusiva figura de Borges.

La literatura aparece como una operación de extrañamiento, de alienación y borrado en pos de una voz y una obra que sólo es concebible si se sacrifica al yo biográfico y a la "verdad" de la historia. Constantemente, la distanciación es equivalente a la escritura, al estilo: "Tomar una biografía real y escribirla como si fuera la mía. Introducir, en ese fárrago de datos extraños, mi tono personal y mi propia conciencia sería un modo de escapar de mí mismo, quedarme sólo con el estilo" (2016a: 146). Y sin embargo, en Renzi, hay cierta autenticidad perdida, algo propio a lo que es Piglia pero "en estado puro" (2001a: 110).

La preocupación por el tema es explícita, es sabido, desde los años sesenta. En 1968 publica una antología que interroga y desmonta el uso del "yo" por los escritores (Gallegos 2012) y en una entrada de los Diarios de 1970, después de constatar que David Viñas es para él un "escritor imaginario", un "actor que hace de escritor", asocia esta dimensión ficticia de la identidad de autor con la necesidad de legitimar a la literatura:

De modo que trataré de hacer una cartografía -o una enciclopedia- de las figuras y las figuraciones del autor en la cultura contemporánea. No es un artista, es un testigo, un cronista y su vida -imaginaria o real- es un intento de justificar -o de comprender- por qué se ha dedicado a la literatura. Esto quiere decir que en esta época la literatura ya no se justifica a sí misma, y hay que legitimarla (2016a: 219).

Dejando de lado el diagnóstico de época (que pareciera referirse más bien a encrucijadas del valor social de la literatura hoy), nótese que la legitimidad de la literatura pasa por la puesta en juego, por no decir el sacrificio, de la propia vida en aras de un "ser escritor", de una identidad de escritor que, en sí, le da trascendencia y valor a lo que se puede llegar a escribir.

Alrededor de todo esto se cristaliza una obsesión, muy presente en los Diarios, que es una fantasía de otra toma de distancia, ahora con respecto al medio y a la actualidad, una fantasía de estar en un contratiempo en relación con las fuerzas dominantes de su época, de aislamiento como utopía de escritura, de escritura pura, en los que el ser social y el ser histórico (los de Ricardo Piglia) se disolviesen en una otredad soñada (la de Emilio Renzi). El lugar y la identidad de escritor tienen que ver con un momento histórico al que se pertenece y que le impide poder escribir la obra ideal, la obra aquella que evitaría la constatación del fracaso.

Este aspecto es un terreno de contradicciones; por un lado, hay en los Diarios un deseo fervoroso de ser totalmente sincrónico de lo contemporáneo, de dialogar de igual a igual con la cultura universal, de estar entonces "en el presente del arte" (2016a: 27), de terminar con la sensación de "estar siempre a destiempo, atrasados, fuera de lugar. Hoy cualquiera de nosotros se siente ligado a Peter Handke o a Thomas Pynchon, es decir logramos ser contemporáneos de nuestros contemporáneos" (2016a: 173). Sin embargo, Piglia se percibe a sí mismo en desfase temporal, viviendo en un tiempo propio que no se corresponde del todo con el del almanaque o el de la biografía: "Como siempre, siento lejos a los escritores de mi generación, como si yo viviera en un tiempo anterior al de ellos" (2016a: 201); o bien: "Mis lecturas de los últimos meses [...] me confirman que llevo cinco años de "atraso" (por lo menos) respecto del resto de mi generación. Leo siempre a destiempo" (2016a: 248). El estar en otro tiempo, tiempo que no es el del almanaque o el de la biografía, incluye fervorosas lecturas de Stendhal (la novela decimonónica como 
sorprendente modelo) o ciertas proyecciones del presente al futuro: "Quisiera vivir esta época del modo en que la recordaré" (2016a: 415). El postulado de la necesidad de una historia literaria basada en modos de leer de los escritores responde a lo mismo: ser escritor es desplazarse del tiempo asignado a la vida a un tiempo de literatura (al tiempo de Renzi). Por eso hay una queja repetida sobre los excesos de solicitación por parte de amigos, en contradicción con la participación de Piglia en instituciones culturales y su ansiedad constante por encontrar compañías amistosas y amorosas. En términos de figuras de lector él ya había desarrollado dos modelos semejantes: el modelo del lector que se encierra y aísla (Kafka) y aquél que se sitúa en la ciudad, en la dispersión y en la multiplicidad de signos (Joyce). Por supuesto, ambos modelos son, en realidad, modelos de escritor (2015b: 18-19).

La escritura es entonces ese paréntesis temporal, ese excluirse de una época, pero también de una experiencia vivida, de un grupo, de un modo de interrelación permanente con un medio intelectual y artístico ("siempre he preferido estar solo" [2016a: 199]), en contradicción con sus sistemáticas intervenciones en ambientes culturales: "Estar en acción, metido en la realidad, es lo que uno de los varios que soy siempre ha buscado" (2016a: 270). Un episodio particularmente claro sobre el conflicto entre el "ser escritor" como identidad aparte, puramente literaria, y el "ser social" entrampado en redes relacionales es el siguiente:

Me encierro, cierro la puerta, clausuro el teléfono, dispuesto a escribir todo el día. Voy a la cocina a prepararme un té y empiezan a sonar a la vez el teléfono y el timbre. Permanezco en la cocina, a oscuras, el timbre suena varias veces. A partir de ahí empieza a sonar cada cinco minutos pero no atiendo, decidido a ganar el día sea como sea pero con una indefinible y extraña sensación de estar haciendo el ridículo. Por supuesto la literatura es mi coartada: lo que busco -lo único que busco- son estas fugas de la realidad. Encerrado, todas las persianas clausuradas, con luz artificial, es como si estuviera ausente (2016a: 240-241).

31 Esa especie de fobia por lo real, paralela a la despersonalización, se materializa luego en una fantasía, la de aislarse en una casa del Tigre durante largas semanas para escribir; ahora bien, cuando por fin se instala allí, no aguanta más de cuarenta y ocho horas, harto "del barro y de los mosquitos" (2016a: 278). Otra vez: la fantasía es una forma de vivirse como escritor, solicitando un espacio de diferencia, una identidad por lo tanto alternativa, fuera de las miradas de los otros y de los discursos de la época, fuera también de los deseos, ilusiones, frustraciones, miedos y angustias del hombre que vive. En los cuadernos está muy presente por lo tanto lo que cabe identificar como una tensión entre la singularización y la pertenencia: rechazo del grupo que impone, búsqueda del grupo en el que se interviene (revistas, editoriales, universidades, pero también acciones políticas). De hecho, más que afuera o en oposición, el lugar es el de un desfase, un intento de desplazamiento, como sucede con la elección del seudónimo.

Volviendo al comienzo, es decir a la película de Di Tella y a la supuesta confesión sobre la idea de publicar los Diarios atribuyéndoselos a Renzi, me parece agudo, en términos expresivos, el desaliento o el temor que acompañan el anuncio de esa decisión; retomando la cita: "No sé si voy a tener el coraje de hacerlo, digamos, es como que yo quedo ahí...". No sabe si va a tener el "coraje" de hacerlo porque eso lo dejaría vacío, borrado, oculto en los puntos suspensivos o en el silencio final de un enunciado trunco: "es como que yo quedo ahí...". Me parece que la frase alude involuntariamente a la problemática, constante, del fracaso y de una expresión bloqueada. En el documental de Di Tella Piglia lee una frase de un cuaderno (publicada en "Diario de un loco", 2000b: 127): 
"Nadie puede decir nada sobre sí mismo, pero sobre otro, es posible, quizá, como quien dice, desatar el nudo que ata el sentido." Al desplazar el nombre del sujeto protagonista de los Diarios esa imposibilidad es asumida, al fracaso se lo integra como operación de ficción, la escritura pasa a ser vivida como experiencia de desposesión (según el juicio de Piglia sobre el diario de Gombrowicz) (2007: 28). Y nótese que la obra no escrita es también aquella, invisible, que, en algunas articulaciones, se le atribuye al mismo Renziautor (Waisman 2017).

La desapropiación, el enajenamiento ante la palabra transformada en palabra del otro, en palabra literaria, funda la impresión de fracaso y alude a una experiencia, también, de pérdida y eventual restauración (Rodríguez Pérsico 2007): nunca se escribe aquello que se sueña escribir, la vida se va en aprontes y proyectos de algo que no llegará: "Un diario se escribe para decir que no se puede escribir" (2017: 54). El escritor se sabe derrotado antes de empezar: "¿Y si lo mejor que yo he escrito, y si lo mejor que yo escribiré en mi vida, fueran estas notas, estos fragmentos, en los que registro que nunca alcanzo a escribir como quisiera?" (2016a: 74), se pregunta en contrapunto a la siempre postergada y ardua redacción de la primera versión de Plata quemada, intitulada entonces Campo de batalla, o en eco a las dudas que rodean la publicación de la primera versión de los cuentos de Nombre falso. $\mathrm{Y}$ en el tercer tomo, el balance es más desalentador aún: "El fracaso es la historia secreta de mi vida, eso es el diario que escribo desde hace veinticinco años" (2017: 154).

El fracaso, omnipresente, cumple aquí una paradójica función idealizadora: se dramatiza aquella gran obra que no se pudo escribir y se exhibe cierta impotencia creadora, haciendo de ese ideal y de esa impotencia, junto con una inteligente sutileza, los paradigmas de una forma particular de negatividad. Una negatividad que se transforma en epopeya del fracaso, vista en muchos escritores (en un momento dado evoca "la autoridad que [le] da el fracaso" (2016a: 390) a Scott Fitzgerald), o sea en una suerte de relato legendario que se corresponde con la creación de una filiación heroica de fracasados, de escritores sin obra o de obra atípica, de marginales o muertos prematuramente, situados en las orillas del éxito: Macedonio, Arlt, Gombrowicz (Blanco Calderón 2008).

Un fracaso a la vez productivo y letal. En algunas articulaciones de la obra y con mucha fuerza en el tercer tomo de los Diarios, el fracaso se superpone con el suicidio y con la muerte, horizontes de desaparición del yo biográfico que queda fuera del juego de lo dicho. Suicidio y fracaso que son el último homenaje rendido a la diosa exigente que resulta ser la literatura, resultado de la despersonalización exacerbada y de un aislamiento tan anhelado como imposible: "Escribir un libro que consista en la aventura de leer mi propio diario. Narrador anónimo. Investiga las causas del fracaso (o del suicidio)" (2017: 113-114). La desaparición no es ajena entonces a un modo de ser escritor que pasa por la desposesión de sí mismo: "Estoy pensando el seudónimo y el doble como una manera no corporal del suicidio. Perderse en otra identidad, desdoblarse, dejar que otro haga el trabajo sucio (por uno)" (2017: 114). La verdad, si la hay, la resolución, si se la puede entrever, están en hacer del fracaso un logro y en la muerte o en el suicidio encontrar un modo de persistencia, más allá de las engañosas apariencias del presente:

La historia literaria es siempre una condena para el que escribe en el presente, allí todos los libros están terminados y funcionan como monumentos puestos en orden como quien camina por una plaza en la noche. Una "verdadera" historia literaria tendría que estar hecha sobre los libros que no se han terminado, sobre las obras 
fracasadas, sobre los inéditos: allí se encontraría el clima más verdadero de una época y de una cultura (2016a: 200).

36 Allí en todo caso se sitúa Piglia, ésa es su obra maestra, no el Gran Libro sino la extendida y brillante escritura del fracaso.

\section{Una fundación postrera}

37 Ser totalmente sincrónico de los escritores de su tiempo y ser anacrónico, leer a Stendhal, alejarse, situarse en un contratiempo; ubicarse en el centro mismo del campo literario, intervenir en revistas, en polémicas, enseñar, fijar nuevas orientaciones críticas, y al mismo tiempo aislarse, elegir la escena de la soledad de escritura como vivencia superior de una vida de autor; intentar transmitir lo más inmediato y fidedigno de la experiencia, dejando trazas del día a día y de lo nimio de la vida cotidiana, pero hacer de la propia vida una ficción, un proyecto que englobe toda la obra por escribir; llegar a ser escritor, lograr que Ricardo Piglia sea escritor, pero fracasando, siendo otro, siendo una vertiente imaginaria de sí mismo, ser Renzi. De eso se trata, ésa es la estrategia, incluso para el futuro, ya que la propuesta para el próximo milenio (la que Piglia agrega a las cinco, de las seis previstas por Italo Calvino y redactadas antes de su muerte) tiene que ver con eso: "el deslizamiento, el desplazamiento, el cambio de lugar. Salir del centro, dejar que el lenguaje hable también en el borde, en lo que se oye, en lo que llega de otro" (2013).

En el gesto de desplazamiento en los significantes de un nombre se juegan entonces los comienzos de Piglia así como los sentidos de un final, su tipo de lecturas de la historia literaria, su relación tortuosa, zigzagueante, con la vivencia y con lo autobiográfico. Es un gesto fundacional que atañe a la identidad pero también el signo que la representa: autofundarse, autoescribirse, como requisito o punto de partida de una obra por venir. Ser otro, ser dos, proyectarse en algo que es él mismo y que está, al mismo tiempo, levemente alejado del yo. En el tercer tomo expresa un deseo de este tipo: "Quisiera poder partir mi vida en dos, ocupar dos sitios, ser otro en cada uno de ellos; tener dos vidas, por lo menos dos vidas, simétricas, concéntricas, ir y volver de un lado al otro, siempre en el tren de las seis de la tarde" (2017: 134).

Ser Piglia y ser otro, ser Renzi. Comparando, otra vez: en varios niveles el fenómeno es simétrico y semejante al que Saer lleva a cabo por esos mismos años (escribir sobre Santa Fe y escribir sobre otro lugar): empezar una obra es borrar el nombre de Santa Fe y elegir para su primer libro de cuentos una denominación, la zona, que implica a la vez la generalización y la apropiación literaria de un espacio determinado. En vez de una identidad de escritor creada, o más bien para crear una figura de autor, se trata en el santafesino de definir un lugar para la escritura, haciendo de ese lugar la condición de posibilidad de una obra en ciernes. En Piglia, se elige la lateralidad del segundo nombre y del segundo apellido para deslizarse hacia una identidad ficticia. Por un lado, borrado del significante, del lugar biográfico y geográfico, nueva fundación a partir de una apropiación de lo conocido (el sustantivo zona en vez del nombre propio Santa Fe) y por lo tanto, paso de lo conocido a lo nuevo. En Piglia, el vaivén entre dos nombres, dos partes, dos filiaciones, crea en los comienzos una disyuntiva, una tensión, un conflicto entre vida y ficción, entre escritor y hombre, entre padre y madre.

En ambos la operación, de espectaculares consecuencias, es simple y concierne un signo, el nombre: ocultar Santa Fe y llamarla con un sustantivo general, la zona, que figura en el 
título del primer libro del autor (En la zona) y que termina siendo un nombre propio, con mayúscula (la Zona de Saer); elegir la lateralidad del segundo nombre y el segundo apellido para cobijarse en una identidad ficticia, una elección que supone un anuncio, un marco ficcional, una adecuación de materiales biográficos a un proyecto que, pareciera, no terminó de organizarse hasta el final.

Porque ésa es la mayor diferencia entre Saer y Piglia: en Saer, hay un envión inicial, nunca desmentido; en Piglia, una coagulación tardía y hasta póstuma de lo que siempre estuvo rondando. Definir el cómo ser escritor (cómo escribir ese nombre, cuál es su nombre) es un acto mayor que, a diferencia de Saer, es entonces retrospectivo. En ese sentido, se parece a la redacción habitual, al final de una vida, de una autobiografía que ordena y jerarquiza los acontecimientos del pasado en función de un efecto postrero (nótese que el volumen más estructurado y controlado de los Diarios, el primero, incluye no menos de once textos de presentación y encuadre, textos que dibujan una forma de autobiografía y establecen por lo tanto una actualización de lo dicho en los cuadernos, puesto en la perspectiva del después, del recuerdo, del balance que da una visión postrera de lo vivido).

Por fin, la alternancia Piglia/Renzi o, mejor, la de las iniciales P/R, sugiere otra analogía, esta vez con Barthes y su célebre S/Z. Si para el francés, S/Z implicaba inversión, espejo, si implicaba el otro lado de la identidad, para Piglia, en $P / R$ es otra cosa lo que está en juego: del otro lado de la barra oblicua, en la $\mathrm{P}$ vuelta $\mathrm{R}$, hay una repetición con un agregado, hay allí algo más, un suplemento de sentido o de trascendencia, un soporte. La R, que es también la de Ricardo -acentuando entonces el gesto de autofundación-, viene alfabéticamente después de la $\mathrm{P}$, como Emilio después de Ricardo, como Renzi después de Piglia. Del otro lado, más allá, se erige la literatura, que "siempre es inactual" y "trabaja con lo que está por venir" (2001b: 39); del otro lado están esas identidades alternativas que fueron primero el contrapunto a una imposibilidad de vivir para terminar siendo, gracias a sus espejeos y transformaciones, un modo de dejar de vivir. En la R que prolonga y completa a la $\mathrm{P}$ se cambia un destino ya terminado, pero también se le escurre el bulto a la muerte.

\section{BIBLIOGRAFÍA}

Balderston Daniel, “El Borges de Piglia”, Teresa Orecchia Havas (ed.), Homenaje a Ricardo Piglia, Buenos Aires, Catálogos, 2012, p. 145-156.

Barthes Roland, Roland Barthes por Roland Barthes, Barcelona, Kairós, 1978.

Blanco Calderón Rodrigo, "Piglia y Gombrowicz: sobre el fracaso y otras estrategias de escritura", Jorge Carrión (ed.), El lugar de Piglia. Crítica sin ficción, Barcelona, Candaya, 2008, p. 27-43.

Carrión Jorge (2008a), "La multiplicación pigliana”, Otro lunes año 2, número 5, Web. Consultado el 19/06/2018.

--- (2008b), "No hay que tomarse en serio a ningún escritor. Entrevista con Ricardo Piglia", El lugar de Piglia. Crítica sin ficción, Barcelona, Candaya, 2008, p. 416-438. 
--- (2017), “La segunda obra maestra de Ricardo Piglia”, New York Times, 1/10/2017, Web.

Consultado el 19/06/2018.

Di Tella Andrés, 327 cuadernos, 2015.

Gallegos Ana, “Quién es quién? Los yo(es) de Ricardo Piglia”, Teresa Orecchia Havas (ed.), Homenaje a Ricardo Piglia, Buenos Aires, Catálogos, 2012, p. 289-304.

González Alvarez José Manuel, En los “bordes fluidos”. Formas híbridas y autoficción en la escritura de Ricardo Piglia, Berna, Peter Lang, 2009.

Kaës René, “Le sujet de l'héritage”, René Kaës, Haydée Faimberg, Micheline Enriquez, Jean-José Baranes, Transmission de la vie psychique entre générations, París, Dunod, 1993, p. 1-58.

Kohan Martín, “Alter ego. Ricardo Piglia y Emilio Renzi, su diario personal”, Adriana Rodríguez Pérsico (comp.), Ejercicios críticos sobre Ricardo Piglia, Landa (Revista do núcleo Onetti de Estudos Literários latino-americanos) vol 5, nº 2, Universidade Federal de Santa Catarina, 2017, p. 261-272, Web. Consultado el 18/06/2019.

Orecchia Havas Teresa, Asedios a la obra de Ricardo Piglia. Essais sur l'œuvre de Ricardo Piglia, Berna, Peter Lang, 2010.

Piglia Ricardo, Prisión perpetua, Buenos Aires, Sudamericana, 1988.

--- (2000a), Formas breves, Barcelona, Anagrama.

--- (2000b), "Diario de un loco", Prisión perpetua, Madrid, Ediciones Lengua de Trapo, p. 127-155.

--- (2001a), Crítica y ficción, Barcelona, Anagrama.

--- (2001b), Tres propuestas para el próximo milenio (y cinco dificultades), Buenos Aires, FCE.

--- "Ideología y ficción en Borges", Grupo de investigación de literatura argentina de la UBA (ed.), Ficciones Argentinas: antología de lecturas críticas, Buenos Aires, Norma, 2004, p. 33-42.

--- “El escritor como lector”, Rose Corral (ed.), Entre ficción y reflexión. Juan José Saer y Ricardo Piglia, México, El Colegio de México, 2007, p. 17-34.

--- "Una propuesta para el próximo milenio", Teresa Orecchia Havas (dir), Homenaje a Ana María Barrenechea, Cuadernos LIRICO n 9, 2013, Web. Consultado el 19/06/2018.

--- (2015a), Los diarios de Emilio Renzi. Años de formación, Barcelona, Anagrama.

--- (2015b), La forma inicial. Conversaciones en Princeton, México, Sexto Piso.

--- (2016a), Los diarios de Emilio Renzi. Los años felices, Barcelona, Anagrama.

--- (2016b), Las tres vanguardias. Saer, Puig, Walsh, Buenos Aires, Eterna Cadencia.

--- Los Diarios de Emilio Renzi. Un día en la vida, Barcelona, Anagrama, 2017.

Rodríguez Pérsico Adriana, “La práctica literaria, entre la pérdida y la restauración”, Rose Corral (ed.), Entre ficción y reflexión. Juan José Saer y Ricardo Piglia, México, El Colegio de México, 2007, p. 137-148.

--- "Los diarios de Emilio Renzi o el pudor autobiográfico", Zama 9, 2017, p. 59-69, Web. Consultado el 19/06/2018.

Villoro Juan y Patricio Pron, "La voluntad de ser irreal. Diálogo sobre Ricardo Piglia", Cuadernos hispanoamericanos, abril 2018, Web. Consultado el 19/06/2018. 
Waisman Sergio, "La obra invisible de Emilio Renzi: lugar incierto, tradición clandestina", Revista Iberoamericana, Vol. LXXXIII, Núm. 258, Enero-Marzo 2017, p. 73-86, Web. Consultado el 19/06/2018.

\section{RESÚMENES}

Lo más destacable de la edición de Los diarios de Emilio Renzi, si dejamos de lado las extraordinarias condiciones biográficas en las que fue preparada, es la renovación y afianzamiento del desliz de una identidad biográfica (la de Ricardo Piglia) a una ficticia (la de Emilio Renzi), ya presente en toda la obra pero que encuentra aquí un desenlace englobante.

En el artículo se estudian algunos procedimientos de ese desplazamiento, sus efectos semánticos y su relación con otras operaciones narrativas. En el cambio del significante de un nombre se cristaliza un mecanismo central del proyecto y se acentúan ciertos sentidos de lo ya escrito.

Si on laisse de côté les extraordinaires conditions de préparation de l'édition de Los diarios de Emilio Renzi, ce qui en est l'aspect le plus remarquable c'est sa manière de rénover et d'asseoir le glissement d'une identité biographique (celle de Ricardo Piglia) à une autre fictionnelle (celle d'Emilio Renzi), glissement déjà présent dans l'œuvre de l'Argentin mais qui trouve ici un dénouement englobant.

L'article étudie quelques procédés relatifs à ce déplacement, leurs effets sémantiques et leur relation avec d'autres dispositifs narratifs. Dans le changement du signifiant d'un nom on voit se cristalliser un mécanisme central du projet littéraire qui tend à emphatiser certains sens de ce qui a déjà été écrit.

Besides the uncommon biographical circumstances in which the edition of Los diarios de Emilio Renzi was prepared, its outstanding feature can be said the renewed passage from a biographical identity (Ricardo Piglia's) to a fictional one (Emilio Renzi's). This slide of identities, already present in Piglia's other works, finds here a more including and posthumous version.

The article analyzes some devices on that issue, their semantic effects and their conexion with other narrative strategies. Changing the name's significant strengthens the main axis of the litterary project and emphasizes the semantics of the previous books.

\section{ÍNDICE}

Palabras claves: Piglia, autobiografía, seudónimo, figura de autor

Keywords: Piglia, autobiography, pseudonym, author's figure

Mots-clés: Piglia, autobiographie, pseudonyme, figure d'auteur

\section{AUTOR}

\section{JULIO PREMAT}

Université Paris 8 - Institut Universitaire de France

ju.premat@wanadoo.fr 